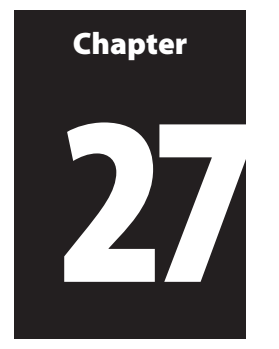

\title{
From Fear and Pity to Parity: Politics and Public Mental Health
}

\author{
Peter Byrne
}

\section{Introduction}

Stigma, fear and pity are deeply intertwined with the history of psychiatry and mental health. This chapter reviews their continued impact during the years 1960-2010 and reasons and efforts to move beyond them towards respect, engaged relationships and social inclusion. It draws on the journey, individual and societal, of a social psychiatrist that began well before I started my first trainee psychiatrist job in Dublin in 1992, a seminal year for UK psychiatry as described in the section '1992: Jonathan Zito, Christopher Clunis and NHS Mental Health Services'. This journey includes thirteen years' experience as Associate Registrar at the Royal College of Psychiatrists.

I had learned at an early age that people with 'mental problems' were different. Back in the 1970s, my grandfather returned one day, upset, from a job as a draughtsman-builder at the local psychiatric asylum in midlands Ireland. He had grown up nearby in the rural poverty of 1920s Ireland, burying four of his six siblings to tuberculosis before they reached the age of eighteen, but even he was shocked by the living conditions he saw then in what locals called the 'looney bin'. His job was a short-term 'fixer-upper' for the wards, perhaps someone had written a bad report or an official was coming to visit. He said he had been told to do the bare minimum lest questions be asked about expenses, and he wanted to do more: 'these people have nothing.' I still have the photo of the outside of the building. We were not allowed in.

A year of two later, at my Dublin secondary school, a classmate reappeared following his first psychiatric admission for bipolar disorder. It should have been a low-key return. Instead, our chemistry teacher started to call him 'mentler'. Jim also used the term looney bin when he talked about it. I said nothing. The abuse continued from that teacher and fellow pupils and Jim did not finish school.

It was the 1970s and Ireland had public service TV ads urging its citizens to stop driving while intoxicated: 'if you give car keys to a drunk man, you might as well hand a loaded shotgun to a lunatic.' I heard language like this, and much worse, within my new profession for the seven years I trained in psychiatry. My last trainee job there was in North County Dublin, another old asylum. There were several long corridors with freshish paint until the turns where the long-stay wards began - with bare, crumbling walls. Did they run out of paint, I asked? No, that is for when health ministers visit: they do not need to go beyond these points. My twenty-one years' experience as a full-time NHS consultant has been different but also similar. In north-east London, a senior manager declined a cup of tea on a visit to our day hospital because we offered her the same cup 'the patients' drink from. 


\section{What the Public Thinks It Knows about Mental Disorders}

My interest developed into why having a mental illness was so less deserving of recognition/ status/empathy than a physical one. I often asked people, well or unwell, what they thought about specific mental disorders, and talked to many psychiatrists and other health professionals, before I started to read the scientific literature. I met many Irish then UK-based colleagues who shared the same interest in public engagement with what we do and how our patients' lives are impacted by stigma and discrimination. One of my east London colleagues, Mark Salter, taught me that 'psychiatrists are the only branch of medicine that need to read the newspapers and go to the cinema'. There was much to review. ${ }^{1}$ I read 'factual' media pages (print and broadcast, online content) and was guided by fictional representations. ${ }^{2}$ Rabkin reflected on responses to the three key messages of an innovative 1960s Canadian educational programme to promote understanding of mental disorders, namely that:

- the range of normal behaviours is wider than often believed

- deviant behaviour is not random but has a cause and can be modified

- normal and abnormal behaviour fall on a continuum and are not qualitatively distinct. ${ }^{3}$

She concluded that 'the third proposition was so unpalatable that the community eventually rejected the entire (six month) educational program(me)'.

Taking Corrigan's definition that stigma is a prejudice based on stereotypes leading to discrimination, ${ }^{5}$ one avenue of study is to explore the stated opinions of the general public towards people with mental disorders. To find out what public attitudes are, work has often used agreement with stereotypical statements as a measure of prejudice. Broader research examines other aspects of public negative attitudes, but here I focus on two: violence perceptions and pity. ${ }^{6}$ Their consequence (discrimination) causes considerable distress to individuals. Even minor avoidance or subtle rejection of people with mental disorders is significant.

Reconceptualisations of psychosis allow for the possibility that stigma-mediated events play a role in relapses of psychosis through the ways these events are evaluated. ${ }^{7}$ Appraisal of events is influenced by reasoning and attributional biases; dysfunctional schemata of self and the world; and isolated or adverse environments. ${ }^{8}$ We can hypothesise similar end results in people with the common mental disorders: anxiety and depression (albeit through different mechanisms such as lowering self-esteem or increasing anticipatory anxiety). ${ }^{9}$

\section{Courting Public Opinion}

The Royal College of Psychiatrists (RCPsych) in the late 1990s funded an anti-stigma campaign led by the late Arthur Crisp, professor of psychiatry at St George's Hospital Medical School. It looked at available research and completed a pre-campaign UK-wide opinion survey. ${ }^{10}$ Changing Minds (aka Every Family in the Land) was run from RCPsych from 1998 to 2003; other campaigns followed, the most enduring ones being See Me in Scotland and Time to Change across England and Wales. These latter two campaigns, or more accurately social movements, continue and do things differently and better: they are user-led (experts by experience) with training and support for people with mental health problems to do media work; they start within communities, not 'top-down', using social plus traditional media when necessary; and they achieve key alliances (celebrities, sporting 
Table 27.1

\begin{tabular}{ll} 
20th Century & 21st Century \\
\hline Mental illness & Mental health \\
Psychiatric patient, patients & Service user, experts by experience \\
Family, husband/wife/partner & Carers \\
Schizophrenic & Person/people with schizophrenia \\
Psycho, lunatic, nut job, etc. $^{11}$ & Known to services, care in community
\end{tabular}

organisations, barbers, taxi drivers, artists). What is required is that, as a society, we now talk about mental disorders, mostly with a new progressive language (see Table 27.1).

Others have placed tackling practical discrimination at the centre of their campaigns, most notably Graham Thornicroft and his international collaborators. ${ }^{12}$ After all, people learn how to conceal racist and other negative attitudes and what they might tell researchers can be at variance with what they believe and how they act. Some have argued that softer language is no practical gain - and some activities, for example challenging distasteful media items, are both stereotype suppression (implying an unwanted rebound) and a distraction from a rights-based approach to reducing stigma. ${ }^{13}$ All great points but, three decades ago, we faced an even greater distraction.

\section{2: Jonathan Zito, Christopher Clunis and NHS Mental Health Services}

Everything changed in 1992. On 17 December, Jonathan Zito (age twenty-seven) was changing trains at Finsbury Park Station (London) when a complete stranger, Christopher Clunis (age twenty-nine), approached him to fatally injure him without any provocation. In the subsequent Clunis Report, ${ }^{14}$ multiple service failures were identified, principally that no service took responsibility to follow up Clunis to maximise his treatment engagement (see also Chapter 23).

I started my first consultant psychiatrist job in Kent, England, in 1999 and the only item left by my immediate predecessor on my office desk was that report. ${ }^{15}$ The UK government fed on this. When mental health services were allocated extra resources from 1999 onwards (as were hospital accident and emergency departments (A\&E), cardiology and cancer), it was to protect public safety and much less to treat mental disorders. The Zito Trust became one of several public bodies to call for more coercion in mental health services, and when it wound down its last chief executive said it had become a 'victim of its own success' ${ }^{16}$

I acknowledge the sudden nature of the violent act that stole Jonathan Zito's life as well as the years of grief of his widow, family and friends. The aftershocks of the homicide, inquiries, government statements and media coverage combined, however, to turn community psychiatry into 'scare in the community'. Widespread assumptions about the violent unpredictability of all aspects of psychosis generalised to other mental disorders, and these stereotypes hardened public attitudes. ${ }^{17}$

Jonathan Zito's homicide spoke to the public's worst fears that severe mental illness (SMI) was hidden in 'normal people' (think Norman Bates in Psycho, 1960); that psychiatrists were 'too soft' to insist on confinement or coercion; and that our treatments don't work 
anyway. At the time, Brian Cooper called this the Iron Triangle of public anxiety and distrust of people with mental illness; an alienated tabloid press; and government policies focused on populist measures. ${ }^{18}$ There was no public appetite for evidence of the declining rates of homicides by people with psychosis over forty years, ${ }^{19}$ and so when the murders (sic) of Lin and Megan Russell occurred in 1998, committed by a stranger who had no psychosis, 'something had to be done'. ${ }^{20}$ It remains hard to fathom the depth of government feeling during these years, such that politicians instructed the civil service (not clinicians) to invent a diagnosis and then legislated to treat it. The Dangerous Severe Personality Disorder (DSPD) diagnosis was conjured up and imposed on psychiatry and mental health. A couple of 'treatment' centres sprang up but, not long after, like the credibility of this 'diagnosis', vanished into a sad chapter of UK psychiatry (see also Chapter 28). ${ }^{21}$

A review of fifteen years of population-based public attitudes research identified differences between disorders, with worse attitudes towards addictions and schizophrenia than towards depression and anxiety. The key difference was perceived to be not 'deviant' behaviour but risk of violence. ${ }^{22}$ The first challenge of public education/ engagement was to facilitate empathy by shifting the focus away from violence. Every time there was a high-profile story, we at RCPsych have 'put out' a small group of media-trained clinicians to counter with arguments about actual incidence of these homicides, ${ }^{23}$ with clear messaging on what is needed (well-resourced general adult psychiatry and community mental health services). Even 9/11 brought psychosis back into the bear pit of public opinion, when then home secretary Jack Straw called bin Laden 'psychotic' in an interview, adding that he 'was picking [his] words with care here because whenever you use the language of mental illness, you get letters from people' ${ }^{24}$ The same Jack Straw drove the DSPD agenda.

\section{'Behaving Strangely'}

This vague, informal two-word descriptor remains the referral headline from my A\&E colleagues. Even within mental health services, clinical work is bedevilled by colleagues failing to differentiate, as evidence and professionalism demand, between functional psychoses (e.g. schizophrenia or bipolar disorder), acute confusional states caused by metabolic and similar abnormalities (delirium) and recreational substance-induced severe but transient mental disturbances; and sometimes also autism.

Successive government policies to outsource NHS addiction services to charities have undermined training in this area and compounded difficulties in both identification and treatment of related clinical problems. One of the clear empirical research messages about violence is that it is true that with stranger assaults the aggressor is far more likely to be intoxicated than be suffering from a functional psychosis. This actuarial statement is never an argument against people with addictions or addictions services. It is an argument in favour of evidence-based anti-alcohol policies such as minimum alcohol pricing. ${ }^{25}$ At the time of writing (2021), only England has neglected to pursue this enlightened public health policy in the UK. In fact, resourced addiction treatment services that engage people, including treatment of comorbid mental disorders, are part of the solution to reduce societal violence due to alcohol and drugs). ${ }^{26}$

The core argument to reduce homicides by people with functional psychosis remains: work for less stigma and discrimination and people will be more likely to present to mental health services, engage well and take agreed medications. More stigma (hysterical media 
headlines, government legislative zeal) and they will more likely present to police than psychiatrists; take medication only under coercion; and use cannabis/other substances that increase the risk of violence. People will then present to services not 'because they are suffering but because they are insufferable'.

\section{Existential Crisis within Psychiatry}

As a clinician who works full-time as a general hospital psychiatrist, seeing patients referred from $A \& E$ and medical and surgical wards, my greatest frustrations relate to having responsibility without power. Often, I return patients home to unspeakable poverty with few or no supportive relationships in their lives. I document but cannot 'fix' their medium-term risks of suicide, coming to physical harm or, much less frequently, a future impulsive moment of violence to others. I am at once responsible but lack the power to make the right changes happen.

As the century began, NHS services in which I worked received 'new money' to assist us to set up five new early intervention in psychosis and general hospital liaison services but frustrations increased as that money dried up or was wasted on needless layers of management (see also Chapter 12). Professor Sir David Goldberg in his lecture on 'NHS psychiatry 1980-2006', referring to mental health services and the overemphasis on fear of psychiatric patients, concluded:

This deterioration occurred despite (Treasurer) Gordon Brown's new money: $£ 172$ million a year between 2001 and 2005. Overall, the King's Fund estimate that 17 per cent of the new money was spent on local service developments, 32 per cent on pay and price infrastructure, and 46 per cent on the NHS Plan and modernisation funds. Furthermore, the National Survey of Investment 2004/2005 revealed a focus on forensic services at the expense of basic provision. Spending on secure and high dependency, access and crisis services and home support rose by 81 per cent, 79 per cent and 75 per cent respectively. The NHS invested far less on new buildings (17.0 per cent increase), CMHT (13.0 per cent), continuing care (11.0 per cent) and clinical services (10.0 per cent). In other words, the new money has been spent on the wrong things. Funds for forensic patients have been given marked preference over improving basic services. ${ }^{27}$

\section{Hitting the Target but Missing the Point}

More than half a century ago, Phillips speculated about the relationship of knowledge to stigma: 'the increased ability of the layman to identify certain behaviours as mental illness does not necessarily imply changes in the way he will act toward persons suffering from mental disease. ${ }^{28}$ Clinical experience has taught me that the A\&E doctor who correctly identified psychosis among the behaving strangely cohort was never more empathic towards this group. Aimed at the public, from the biomedical corner, public talk of 'brain disorders ... biochemical imbalances' was followed by a decade or so of raising awareness about mental health and well-being (whatever that is). It is hard to prove this hypothesis, but the more universally mental health has been discussed, and despite sound general advice (exercise more, value your friendships), the greater the distancing and neglect of people with SMI. A review of the literature has shown that the 'illness like any other' approach to the stigma of schizophrenia increases perceptions of violence and the public's desire for more social distance. $^{29}$ 


\section{'Beware Pity: It's About Parity'}

More recently, and with fewer 'scares in the community' stories gaining media traction, we see new images, literally the stock photo images in print and online of what journalists/ subeditors think mental disorders look like - principally, 'headclutchers' ${ }^{30}$ These are individuals with their heads bowed, hiding their distress and their secrets in both hands, with fingers splayed. With a sense of mystery as to what led them to here and a loss of personhood, they evoke pity and discourage interaction with others. Anti-stigma campaigners have mounted a spirited response, and a BBC News account called for 'more sympathy (sic) for those affected'. ${ }^{31}$ Even complementary newspaper articles that covered the former UK prime minister David Cameron's declared 'mental health revolution' in 2016 gave us another headclutcher. ${ }^{32}$ This time, as usual, the money did not follow the rhetoric: antistigma talk was cheap.

My experiences of this decade in briefing journalists, lobbying in Westminster, and working with some trustees of UK mental health charities were similar. What I encountered was not rights-based, social justice mindsets but pity-led motivations. Perhaps as a shortterm strategy asking for funding because 'these people have nothing' seems the only way to achieve what is needed. The public mood had changed (perhaps Jack Straw's 'letters from people' has evolved to censure in the social media) and 'these people' are now thought to deserve our sympathy and a better deal. However, listening to the warm words of journalists, politicians and charity grandees, there comes to mind Prince Lampedusa's response to Garibaldi's revolutionary campaign to unify Italy in the novel The Leopard: 'things must change so that they can stay the same.'

There is no need to read the stigma literature to know that high public perceptions of danger generate avoidance and more distance from people with psychosis. Equally, we would not like to be in a relationship or get a new job merely because someone felt sorry for us. Stigma-based discrimination is about social relationships, but those where there is a power differential (between stigmatiser and stigmatised): pity from powerful others is internalised and makes people more hopeless over time, just as it lowers self-esteem and has the potential to provoke depression. ${ }^{33}$

The employment example makes a wider point. Less than 15 per cent of people with SMI are in paid employment, lower even than low European comparisons. These scandalous rates are not about ability or potential; they reflect an abundance of employer sympathy ('this job might be too much for them') and a lack of empathy (to enquire of 'them' what adjustments might be needed, if any, to support them in this employment). We asked our early intervention patients with a recovered psychosis what they wanted. They said jobs, relationships and housing. Within the two multidisciplinary early intervention psychosis teams where I have worked with nurses, support workers and vocational rehabilitation specialists, I have seen many young people with psychosis achieve employment, often their first job. We assumed only that they would recover. On reflection, the very fact that we supported them to stay out of hospital, or the 'looney bin', helped employers see their potential not their deficits.

\section{Pity Can Seriously Damage Your Health}

Recent collaborations with ASH (Action on Smoking and Health) as part of the mental health smoking partnership have revealed another aspect of pity over parity. The Stolen Years report identified cigarette smoking as the main preventable cause of the seventeen- 
year average reduction in life expectancy among people with SMI. Seventeen years of life lost and the final years of life are blighted with cardiovascular disorders, stroke, respiratory illnesses and smoking-related cancers: the stolen years. ${ }^{34}$ As mental health Trusts went smoke-free (banning smoking on their premises), some psychiatrists called for 'exceptions'. They cited human rights, but no one has a right to smoke in a hospital building. Next came the arguments that psychiatric patients were different from general hospital patients and that:

- 'I couldn't expect my patient to quit smoking during a crisis';

- 'If we grab their cigarettes, they will become violent'; and

- 'It's all they have ... let them smoke'.

For me, this is three decades in one exchange: violence, pity and low expectations. In case I sound too severe, we do not ask people to give up (highly addictive) nicotine but are insisting that they do not smoke cigarettes in our hospitals. This is also about the rights of other patients and staff to healthy smoke-free environments. We provide nicotine replacement and multiple resources, including electronic cigarettes, as well as access to quit programmes that include varenicline. The evidence is clear: people with SMI want to quit just as much as any smoker and achieve high quit rates with the right options; and violence on psychiatric wards has reduced since the smoking ban. ${ }^{35}$

\section{Conclusion}

I was too young to interrogate my grandfather's response to the inhumane conditions cited in the Introduction to this chapter; was it pity or might it have been what Patrick Corrigan calls 'righteous anger'? Fifteen years after school made life hell for Jim, I met him when I was resident on call to the psychiatric unit where he had been sectioned (against his wishes). It was a quiet night for both of us and I made some tea. I did not tell him how sorry I felt for his life course, but I got the chance to apologise for my silence when others harassed him. He laughed it off and then told me some tales 'from the other end of the hypodermic needle'. The worst of his experiences were outside health services, and he set me on a path of learning about poverty and inequality. ${ }^{36}$

Effective community mental health services require an understanding of the communities we serve. This goes beyond cultural and subcultural beliefs. The community's main concerns (their safety, young people who self-harm, seeing 'homeless people' who look mentally unwell) will change over time. When governments and others exploit these attitudes, we (psychiatrists and other mental health professionals) need to call this out. The public wants to know and engage with psychosocial explanations of distress and mental disorders, even self-harm and suicide. Social psychiatry, now public mental health, encompasses an understanding of the factors (poverty and inequality, adverse childhood experiences, structural inequalities, discrimination and daily stress, etc.) that cause and perpetuate mental disorders. We must use this evidence to pursue prevention, ensure treatment plans are properly resourced and address underlying social causes of mental disorders.

\section{Key Summary Points}

- Historical fears of violence by people with mental disorders increased in the final years of the last century. Science demonstrated falling UK homicide rates by people with psychosis, but inaccurate perceptions drove UK government policy instead. 
- As the public perception of violence subsides, we see increasing societal narratives of pity for people who lose their mental health; these will mostly serve to extend their exclusion and deepen inequalities. Pity makes people ill.

- Actions to highlight and reduce stigma and discrimination have softened some attitudes, but mental health awareness is no substitute for actual engagement with people who have mental disorders and sustainable funding for those that need state support (housing, income) or health services.

- Clinicians and partners in mental health reform have a duty to engage with local communities (and sometimes beyond) to achieve sufficient degrees of public engagement to prevent mental disorders by reducing the causes, principally poverty and inequality. These actions are just as important as providing fully integrated community mental health services.

- Parity of esteem is never having to say you are sorry (for someone) but to collaborate/ advocate for their rights.

\section{Notes}

1. Personal communication (verbal) with Dr Mark Salter. See also P. W. Corrigan and B. Gelb, Three programs that use mass approaches to challenge the stigma of mental illness. Psychiatric Services (2006) 57: 393-8; P. W. Corrigan, A. C. Watson and F. E. Miller, Blame, shame, and contamination: The impact of mental illness and drug dependence stigma of family members. Journal of Family Psychology (2006) 20: 239-46; P. Byrne, Stigma of mental illness and ways of diminishing it. Advances in Psychiatric Treatment (2000) 6: 65-72; P. Byrne, Psychiatry and the media. Advances in Psychiatric Treatment (2003) 9: 135-43; G. Thornicroft, E. Brohan, D. Rose et al., Global pattern of experienced and anticipated discrimination against people with schizophrenia: A cross sectional survey. Lancet (2009) 373: 408-15.

2. Byrne, Psychiatry and the media.

3. J. Rabkin, Opinions about mental illness: A review of the literature. Psychological Bulletin (1972) 77: 153-71; E. Cummings and J. Cummings, Closed Ranks: An Experiment in Mental Health. Cambridge, MA: Harvard University Press, 1957.

4. Ibid.

5. Corrigan and Gelb, Three programs that use mass approaches to challenge the stigma of mental illness; Corrigan, Watson and Miller, Blame, shame, and contamination.

6. Corrigan and Gelb, Three programs that use mass approaches to challenge the stigma of mental illness; Corrigan, Watson and Miller, Blame, shame, and contamination; Thornicroft, Brohan, Rose et al., Global pattern of experienced and anticipated discrimination; M. Aichberger and N. Sartorius (2006); see the annotated bibliography of selected publications and other materials related to stigma and discrimination in Publications (Books and Journals) of Members of the World Psychiatric Association's Section on Stigma and Mental Disorders (2006 to 2010) as part of the World Psychiatric Association Global Programme to reduce the stigma and discrimination because of schizophrenia, www.queensu.ca /sites/default/files/assets/pages/principal/docs/WPAPublications2006to2010.pdf; M. C. Angermeyer and S. Dietrich, Public beliefs about and attitudes to people with mental illness: A review of population studies. Acta Psychiatrica Scandinavica (2006) 113: 163-79; A. H. Crisp, M. Gelder, S. Rix et al., Stigmatisation of people with mental illnesses. British Journal of Psychiatry, (2000) 177: 4-7; A. H. Crisp, M. Gelder, E. Goddard et al., Stigmatisation of people with mental illnesses: A follow-up study within the Changing Minds campaign of the Royal College of Psychiatrists. World Psychiatry (2005) 4: 106-13; L. Magliano, C. De Rosa, A. Fiorillo et al., National Mental Health Project Working Group: Perception of patients' unpredictability and beliefs on the causes and consequences of schizophrenia. A community survey. Social Psychiatry and Psychiatric Epidemiology (2004) 39: 410-16. 
7. P. A. Garety, E. A. Kuipers, D. Fowler, D. Freeman and P. Bebbington, A cognitive model of the positive symptoms of psychosis. Psychological Medicine (2001) 31: 189-95.

8. Ibid.

9. A. W. Fominaya, P. W. Corrigan and N. Rusch, The effects of pity on self- and other-perceptions of mental illness. Psychiatry Research (2016) 241: 159-64.

10. Crisp, Gelder, Rix et al., Stigmatisation of people with mental illnesses.

11. D. Rose, G. Thornicroft, V. Pinfold and A. Kassam, 250 labels used to stigmatise people with mental illness. BMC Health Services Research (2007) 7: 97.

12. Thornicroft, Brohan, Rose et al., Global pattern of experienced and anticipated discrimination.

13. P. W. Corrigan, Lessons learned from unintended consequences about erasing the stigma of mental illness. World Psychiatry (2016) 15: 67-73.

14. J. H. Ritchie, D. Dick and R. Lingham, The Report of the Inquiry into the Care and Treatment of Christopher Clunis. London: HMSO,1994.

15. Ibid.

16. O. Bowcott, Jayne Zito: Why it's time to end the campaign. The Guardian, 17 May 2009.

17. Angermeyer and Dietrich, Public beliefs about and attitudes to people with mental illness; Crisp, Gelder, Rix et al., Stigmatisation of people with mental illnesses; Crisp, Gelder, Goddard et al., Stigmatisation of people with mental illnesses: A follow-up study; Magliano, De Rosa, Fiorillo et al., National Mental Health Project Working Group.

18. B. Cooper, Public health psychiatry in today's Europe: Scope and limitations. Social Psychiatry and Psychiatric Epidemiology (2001) 36: 169-76.

19. P. J. Taylor and D. Gunn, Homicides by people with mental illness: Myth and reality. British Journal of Psychiatry (1999) 174: 9-14.

20. Home Affairs Committee, Managing Dangerous People with Severe Personality Disorder, https://publications .parliament.uk/pa/cm199900/cmselect/cmhaff/42/4203.htm.

21. A. Feeney, Dangerous severe personality disorder. Advances in Psychiatric Treatment (2003) 3: 349-58.

22. Angermeyer and Dietrich, Public beliefs about and attitudes to people with mental illness.

23. Taylor and Gunn, Homicides by people with mental illness.

24. See Byrne, Psychiatry and the media. The fact that a serving Home Secretary did not know what psychosis is was also written up by Nicholas Watt in The Guardian: Watt, Bin Laden is psychotic, The Guardian, 6 November 2001, www.theguardian.com/politics/2001/nov/06/september11.uksecurity.

25. T. Babor, Alcohol: No Ordinary Commodity: Research and Public Policy. Oxford: Oxford University Press, 2010 .

26. K. Bhui, P. Byrne, D. Goslar and J. Sinclair, Addiction care in crisis: Evidence should drive progressive policy and practice. British Journal of Psychiatry (2019) 215: 702-3, https://doi.org/10.1192/bjp.2019.158.

27. Goldberg lecture. Author's private collection. Goldberg makes similar comments and is cited in J. Turner, R. Hayward, K. Angel et al., The history of mental health services in modern England: Practitioner memories and the direction of future research. Medical History (2015) 59: 599-624, https://doi.org/10.1017/mdh .2015.48,

28. D. L. Phillips, Public identification and acceptance of the mentally ill. American Journal of Public Health (1966) 56: 755-63.

29. J. Read, N. Haslam, L. Sayce and E. Davies, Prejudice and schizophrenia: A review of the 'mental illness is an illness like any other' approach. Acta Psychiatrica Scandinavica (2006) 114: 303-18.

30. The quote in this section's subtitle is from Corrigan, Lessons learned. For examples of 'headclutcher' stock images, see the search results on Google Images for 'mental health stock photos': www.google.com/search? 
source $=$ univ\&tbm $=$ isch \&q=mental+health+stock + photo\&sa=X\&ved=2ahUKEwju6p_q_KLrAhXlQUEAH c6RAaYQsAR6BAgKEAE\&biw=1513\&bih=758.

31. K. Hawkins, Mental health and the death of the 'headclutcher' picture. BBC News, 13 April 2005, www .bbc.co.uk/news/blogs-ouch-32084441.

32. T. Ross, David Cameron makes personal commitment to helping mental health sufferers. The Telegraph, 13 February 2016, www.telegraph.co.uk/news/politics/david-cameron/12156058/David-Cameron-makespersonal-commitment-to-helping-mental-health-sufferers.html.

33. Fominaya, Corrigan and Rusch, The effects of pity on self- and other-perceptions of mental illness.

34. ASH (Action on Smoking and Health), The Stolen Years: The Mental Health and Smoking Action Report, 2016, https://ash.org.uk/information-and-resources/reports-submissions/reports/the-stolen-years/.

35. Ibid.

36. P. Byrne and A. James, Placing poverty-inequality at the centre of psychiatry. BJPsych Bulletin (2020) 44: 187-90. 